\title{
Visible and Near-Infrared Luminescence of Lanthanide-Containing Dimetallic Triple-Stranded Helicates: Energy Transfer Mechanisms in the $\mathrm{Sm}^{\mathrm{III}}$ and $\mathrm{Yb}^{\mathrm{III}}$ Molecular Edifices
}

\author{
Fabiana R. Gonçalves e Silva, ${ }^{\dagger}$ Oscar L. Malta, ${ }^{\ddagger}$ Christine Reinhard, ${ }^{\S}$ Hans-Ulrich Guidel, $\$$ \\ Claude Piguet," Jacques E. Moser, ${ }^{\perp}$ and Jean-Claude G. Buinzli*, $\dagger$ \\ Swiss Federal Institute of Technology Lausanne, Institute of Molecular and Biological Chemistry, BCH, \\ CH-1015 Lausanne, Switzerland, Departamento de Química Fundamental-UFPE, \\ 50740-540 Recife, PE-Brazil, Department of Chemistry \& Biochemistry, University of Bern, \\ CH-3000 Bern 9, Switzerland, Department of Inorganic Chemistry, University of Geneva, \\ CH-1211 Geneva-4, Switzerland, and Swiss Federal Institute of Technology Lausanne, \\ Institute of Molecular and Biological Chemistry, Laboratory for Photonics \& Interfaces, \\ CH-1015 Lausanne, Switzerland
}

Received: July 26, 2001; In Final Form: November 20, 2001

\begin{abstract}
The photophysical properties of the triple-stranded dimetallic helicates $\left[\mathrm{Ln}_{2}\left(\mathrm{~L}^{\mathrm{C}}-2 \mathrm{H}\right)_{3}\right] \cdot \mathrm{H}_{2} \mathrm{O}(\mathrm{Ln}=\mathrm{Nd}, \mathrm{Sm}$, $\mathrm{Dy}, \mathrm{Yb}$ ) are determined in water and $\mathrm{D}_{2} \mathrm{O}$ solutions, and energy transfer processes are modeled for $\mathrm{Sm}^{\mathrm{III}}$. The luminescence of $\mathrm{Nd}^{\mathrm{III}}, \mathrm{Sm}^{\mathrm{III}}$, and $\mathrm{Yb}^{\mathrm{III}}$ is sensitized by $\left(\mathrm{L}^{\mathrm{C}}-2 \mathrm{H}\right)^{2-}$, but the energy transfer from the ligand to the $\mathrm{Ln}^{\mathrm{III}}$ ions is not complete, resulting in residual ligand emission. The luminescence of the $\mathrm{Nd}^{\mathrm{III}}$ helicate is very weak due to nonradiative de-excitation processes. On the other hand, the $\mathrm{Yb}^{\mathrm{III}}$ and $\mathrm{Sm}^{\mathrm{III}}$ helicates exhibit fair quantum yields, $1.8 \%$ and $1.1 \%$ in deuterated water, respectively. The energy transfer rates between $\left(\mathrm{L}^{\mathrm{C}}-2 \mathrm{H}\right)^{2-}$ and $\mathrm{Sm}^{\mathrm{III}}$ levels are calculated by direct and exchange Coulomb interaction models. This theoretical modeling coupled to numerical solutions of the rate equations leads to an estimate of the emission quantum yields in $\mathrm{H}_{2} \mathrm{O}$ and $\mathrm{D}_{2} \mathrm{O}$, which compares favorably with experimental data. The main component of the ligandto-metal energy transfer $(97.5 \%)$ goes through a ${ }^{3} \pi \pi^{*} \rightarrow{ }^{5} \mathrm{G}_{5 / 2}{ }^{(1)}$ path, and the operative mechanism is of the exchange type. For the $\mathrm{Yb}^{\mathrm{III}}$ helicate, minor effects of oxygen on the sensitization of $\mathrm{Yb}^{\mathrm{III}}$ and nanosecond time-resolved spectroscopy point to the energy transfer mechanism being consistent with a recently proposed pathway involving fast electron transfer and $\mathrm{Yb}^{\mathrm{II}}$. No up-conversion process could be identified. Ligand-field splitting of the ${ }^{2} \mathrm{~F}_{5 / 2}\left(3 \mathrm{E}_{1 / 2}+\mathrm{E}_{3 / 2}\right)$ and ${ }^{2} \mathrm{~F}_{7 / 2}\left(2 \mathrm{E}_{1 / 2}+\mathrm{E}_{3 / 2}\right)$ levels of $\mathrm{Yb}^{\mathrm{III}}$ is consistent with $D_{3}$ symmetry.
\end{abstract}

\section{Introduction}

Luminescent lanthanide-containing compounds present unique spectroscopic properties, such as long luminescent lifetimes and line-like emission of the metal ions. These features are presently used in the design of structural $^{1}$ and analytical ${ }^{2}$ luminescent probes, labels for proteins and nucleic acids, ${ }^{3}$ and of lightemitting sensors for hetero- ${ }^{4}$ and homogeneous ${ }^{5}$ fluoroimmunoassays. The development of Ln-containing responsive systems for biomedical analyses has long focused on $\mathrm{Eu}^{\mathrm{III}}$ and $\mathrm{Tb}^{\mathrm{III}}$ probes, as is the work aimed at engineering organic electroluminescent devices for light emitting diodes. ${ }^{6}$ However, the need for multiple fluoroimmunoassays is now prompting the use of the luminescence of other $\mathrm{Ln}^{\mathrm{III}}$ ions, for instance, $\mathrm{Sm}^{\mathrm{III}}$ and Dy ${ }^{\mathrm{III}}{ }^{7}$ while probing chiro-optical effects is leading to pioneer work with $\mathrm{Ln}^{\mathrm{III}}$ ions emitting in the NIR, e.g., Yb ${ }^{\mathrm{III}} .8,9$ The latter interest is further amplified by the development of organic lanthanide complexes for polymer-based optical amplifiers operating at 1.3 and $1.5 \mu \mathrm{m} .{ }^{10}$

We have recently synthesized a series of lanthanide dimetallic helicates $\left[\mathrm{Ln}_{2}\left(\mathrm{~L}^{\mathrm{C}}-2 \mathrm{H}\right)_{3}\right] \cdot n \mathrm{H}_{2} \mathrm{O}$ obtained by self-assembly pro-

\footnotetext{
* Corresponding author.

Swiss Federal Institute of Technology Lausanne, BCH.

Departamento de Química Fundamental-UFPE.

$\S$ University of Bern.

"University of Geneva.

${ }^{\perp}$ Swiss Federal Institute of Technology Lausanne, Laboratory for Photonics \& Interfaces
}

\section{CHART 1}

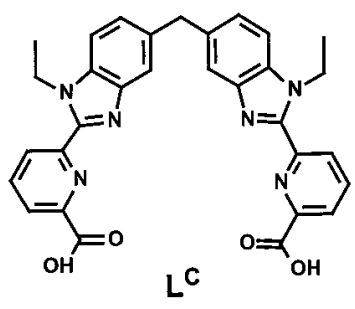

cess in water from ligand $\mathrm{L}^{\mathrm{C}}$ and lanthanide salts, where $\mathrm{L}^{\mathrm{C}}=$ bis $\{1$-ethyl-2-[(6'-carboxy)pyridin-2'-yl]benzimidazol-5-yl $\}$ methane (see Chart 1). ${ }^{11}$ These molecular edifices represent a new class of highly stable carboxylates soluble in water, which is a mandatory characteristic for bioanalytical applications. In these triple-stranded helicates, the metal ion is well protected from solvent interaction and despite its lack of an efficient chromophoric substituent, $\left(\mathrm{L}^{\mathrm{C}}-2 \mathrm{H}\right)^{2-}$ sensitizes the $\mathrm{Eu}^{\mathrm{III}} \mathrm{lu}-$ minescence reasonably well. ${ }^{11}$

Since these helicates are stable and water-insensitive, we now examine the ability of $\left(\mathrm{L}^{\mathrm{C}}-2 \mathrm{H}\right)^{2-}$ to sensitize other $\mathrm{Ln}^{\mathrm{III}}$ ions $(\mathrm{Ln}=\mathrm{Nd}, \mathrm{Sm}, \mathrm{Dy}$, and $\mathrm{Yb})$ in aqueous solutions and in the $\mathrm{pH}$ range $7-12$. The design of lanthanide-containing luminescent probes is not an easy task in view of the numerous energy transfer processes involved and of the many constraints on both the chemical and photophysical properties of the receptor. ${ }^{12}$ Therefore, efficient modeling of these processes would bring a 
better understanding of the crucial features needed and facilitate the choice of a convenient synthetic strategy. Such modeling has been proposed for $\mathrm{Eu}^{\mathrm{III}}$ complexes, ${ }^{13}$ and we have recently used this procedure to understand the luminescence quenching in a triple helical monometallic Eu ${ }^{\mathrm{III}}$ complex with a ligand derived from bis(benzimidazole)pyridine (L). ${ }^{14}$ We now extend this modus operandi to $\mathrm{Sm}^{\mathrm{III}}$ and present, for the first time, calculations of energy transfer rates and emission quantum yields for this ion. The mechanism of $\mathrm{Yb}^{\mathrm{III}}$ sensitization is also discussed on the basis of time-resolved spectroscopy.

\section{Experimental Part and Methods}

Syntheses. Ligand $\mathrm{L}^{\mathrm{C}}$ was synthesized as previously described. ${ }^{11}$ Solutions of the helicates were prepared as follows. A solution of $\mathrm{L}^{\mathrm{C}}(6 \mathrm{mg}, 0.010 \mathrm{mmol})$ in $4 \mathrm{~mL}$ of freshly bidistilled water or $\mathrm{D}_{2} \mathrm{O}$ (99.99\%, from ARMAR) was stirred at $295 \mathrm{~K}$ for $30 \mathrm{~min}$; $\mathrm{NaOH}$ (from Merck) or $\mathrm{NaOD}\left(40 \%\right.$ in $\mathrm{D}_{2} \mathrm{O}$, Fluka) was added dropwise, and the mixture was stirred at 295 $\mathrm{K}$ for $30 \mathrm{~min}$. A solution of $0.007 \mathrm{mmol}$ of $\mathrm{Ln}\left(\mathrm{ClO}_{4}\right) \cdot n \mathrm{H}_{2} \mathrm{O}$ $(\mathrm{Ln}=\mathrm{Sm}, \mathrm{Yb}, \mathrm{Dy}$, and $\mathrm{Nd} ; n=8.8,6.34,7$, and 4.98, respectively) in $2 \mathrm{~mL}$ of water or $\mathrm{D}_{2} \mathrm{O}$ was added dropwise, and the mixture was stirred for $2 \mathrm{~h}$ at $295 \mathrm{~K}$. The solvents used to prepare these solutions were thoroughly degassed. The perchlorate salts $\mathrm{Ln}\left(\mathrm{ClO}_{4}\right)_{3} \cdot n \mathrm{H}_{2} \mathrm{O}$ were prepared from corresponding oxides (Rhône-Poulenc, $99.99 \%$ ) in the usual way. ${ }^{15}$ (Caution! Perchlorate salts combined with organic ligands are potentially explosive and should be handled in small quantities and with adequate precautions. ${ }^{16}$ ) The $\mathrm{pH}$ and $\mathrm{pD}$ of the solutions were adjusted with $\mathrm{NaOH}$ and $\mathrm{NaOD}$, respectively, and were measured with a Metrohm 6.3013.210 glass electrode. The final $\mathrm{pH}$ was corrected for a deuterium isotope effect by using the equation $\mathrm{pD}=\mathrm{pH}+0.4 .^{17}$

Physicochemical Measurements. UV/vis spectra were recorded at $22{ }^{\circ} \mathrm{C}$ on a Perkin-Elmer Lambda 900 spectrometer with the help of quartz cells of 1 and $0.1 \mathrm{~cm}$ path length. Excitation and emission spectra of the ligand and of its $\mathrm{Sm}^{\mathrm{III}}$ complex were recorded on a Perkin-Elmer LS-50B spectrometer equipped for both room- and low-temperature measurements. The luminescence spectra of the $\mathrm{Nd}^{\mathrm{III}}$ and $\mathrm{Yb}^{\mathrm{III}}$ helicates were recorded with a Fluorolog-3 (TRIAXSERIES 320) spectrometer from Spex Industries. Luminescence and excitation spectra are corrected for the instrumental function. Lifetimes are averages of at least five independent determinations.

Continuous-wave luminescence and excitation measurements for the $\mathrm{Yb}^{\mathrm{III}}$ helicate were performed by using a Ti:sapphire laser (Spectra Physics 3900S), pumped by an argon-ion laser (Spectra Physics 2060-10 SA) in all-lines mode. Wavelength control was achieved by an inchworm-driven (Burleigh PZ-501) birefringent filter, and the wavelength was monitored with a Burleigh WA2100 wavemeter. The sample luminescence was dispersed by a $0.85 \mathrm{~m}$ double monochromator (Spex 1402) using $500 \mathrm{~nm}$ blazed 1200 grooves/mm gratings and detected by a cooled photomultiplier (Hamamatsu 3310-01) and a photoncounting system (Stanford Research SR400). All the spectra were corrected for the sensitivity of the monochromator and detection system and for the refractive index of air (vacuum correction). They are represented as number of photons per second versus wavenumbers. The excitation spectra were corrected for the wavelength dependence of the output power of the Ti:sapphire laser.

The $\mathrm{Yb}^{\mathrm{III}}$ lifetimes were measured both on the high-resolution instrument described earlier ${ }^{11}$ and on a pulsed instrument. Pulsed laser excitation was applied to a sample solution, contained in a $1 \mathrm{~cm}$ quartz cell, using a frequency-tripled Q-switched
Nd:YAG laser (Continuum Powerlite 7030, $30 \mathrm{~Hz}$ repetition rate, wavelength $355 \mathrm{~nm}$, pulse width at half-height $7 \mathrm{~ns}$ ). The pulse energy was typically restricted to less than $5 \mathrm{~mJ}$ to prevent rapid degradation of the sample. The emission from the solution was collected at right angle to the excitation beam by a 2 " planoconvex lens, passed through various optical elements, a $1 / 8 \mathrm{~m}$ grating monochromator (Oriel model 77250) and was finally detected by a fast red-sensitive photomultiplier tube (Hamamatsu R928), only three dynodes of which were employed. Light scattered by the sample and the cell walls was blocked before the monochromator by a $400 \mathrm{~nm}$ cutoff filter. A $1 \mathrm{GHz}$ bandpass digital signal analyzer (Tektronix DSA 602A) was employed to record the time course of the laser-induced emission. Satisfactory signal-to-noise ratios were typically obtained by averaging over several hundreds laser shots.

The quantum yields were calculated using the following equation:

$$
Q_{\mathrm{x}} / Q_{\mathrm{r}}=\left[A_{\mathrm{r}}\left(\lambda_{\mathrm{r}}\right) / A_{\mathrm{x}}\left(\lambda_{\mathrm{x}}\right)\right]\left[I\left(\lambda_{\mathrm{r}}\right) / I\left(\lambda_{\mathrm{x}}\right)\right]\left[n_{\mathrm{x}}^{2} / n_{\mathrm{r}}^{2}\right]\left[D_{\mathrm{x}} / D_{\mathrm{r}}\right]
$$

in which subscript $\mathrm{r}$ stands for the reference and $\mathrm{x}$ for the samples; $A$ is the absorbance at the excitation wavelength, $I$ is the intensity of the excitation light at the same wavelength, $n$ is the refractive index $\left(n=1.328\right.$, in $\mathrm{D}_{2} \mathrm{O}$, and $n=1.333$, in $\mathrm{H}_{2} \mathrm{O}$ ), and $D$ is the measured integrated luminescence intensity. Emission band areas were corrected, when needed, for the Raman and Rayleigh diffusion bands, by subtracting the spectrum of the solvent alone. Concentrations and excitation wavelengths of the reference and sample were chosen to generate an absorbance $<0.05$, for which a linear relationship between the intensity of the emitted light and the concentration of the absorbing species is found. ${ }^{18}$ Degassed solvents were used to avoid a possible quenching of the ligand triplet state by oxygen. The standards used to determine the quantum yield of the $\mathrm{Sm}^{\mathrm{III}}$ helicate were quinine sulfate in $0.5 \mathrm{M} \mathrm{H}_{2} \mathrm{SO}_{4}(n=$ $\left.1.338, Q_{\text {abs }}=0.546^{19}\right)$, cresyl violet $1.4 \times 10^{-5} \mathrm{M}$ in $\mathrm{MeOH}(n$ $\left.=1.329, Q_{\mathrm{abs}}=0.54^{20}\right)$, and $\left[\mathrm{Ru}(\text { bipy })_{3}\right]^{2+} 6 \times 10^{-5} \mathrm{M}$ in water $\left(n=1.333, Q_{\mathrm{abs}}=0.042^{21}\right)$, where bipy stands for $2,2^{\prime}$ bipyridine. These standards possess an absorbance in the UV region similar to that of the $\mathrm{Sm}^{\mathrm{III}}$ helicate, and the last two ones exhibit emission in the same wavelength range than $\mathrm{Sm}^{\mathrm{III}}$. Ligand-centered luminescence was measured relative to quinine sulfate in $0.5 \mathrm{M} \mathrm{H}_{2} \mathrm{SO}_{4}$. The $\left[\mathrm{Yb}(\mathrm{TTA})_{3}\right.$ ] complex, TTA = thenoyltrifluoroacetonate, was used as reference to determine the quantum yield of the metal-centered luminescence in $\left[\mathrm{Yb}_{2}-\right.$ $\left.\left(\mathrm{L}^{\mathrm{C}}-2 \mathrm{H}\right)_{3}\right]$. The $\left[\mathrm{Yb}(\mathrm{TTA})_{3}\right]$ complex was synthesized according to the published method. ${ }^{22}$ The emission quantum yield of this complex in toluene solution $(n=1.4964)$ was taken as $Q_{\text {abs }}=0.35 \% .^{23}$

Theoretical Models Used. ${ }^{13,24}$ As previously shown, the various contributions to the ligand-to-rare earth ion energy transfer rates $W_{\mathrm{ET}}$ may be described by the following expressions $1-3:^{25}$

$$
W_{\mathrm{ET}}^{\mathrm{mp}}=\frac{2 \pi}{\hbar} \frac{e^{2} S_{\mathrm{L}}}{(2 J+1) G} F \sum_{\lambda} \gamma_{\lambda}\left\langle\alpha^{\prime} J^{\prime} \| U^{(\lambda)}|| \alpha J\right\rangle^{2}
$$

describes the contribution of the dipole- $2^{\lambda}$ pole mechanism $(\lambda$ $=2,4$, and 6), with

$$
\gamma_{\lambda}=(\lambda+1) \frac{\left\langle r^{\lambda}\right\rangle^{2}}{\left(R_{\mathrm{L}}^{(\lambda+2)}\right)^{2}}\left\langle 3\left\|C^{(\lambda)}\right\| 3\right\rangle^{2}\left(1-\sigma_{\lambda}\right)^{2}
$$


TABLE 1: Values of the Matrix Elements Used in the Analysis of the Energy Transfer Process in the $\mathrm{Sm}^{\mathrm{III}} \mathrm{Helicate}^{\mathrm{I}}$

\begin{tabular}{|c|c|c|c|c|}
\hline & $\lambda=2$ & $\lambda=4$ & $\lambda=6$ & \\
\hline$\left\langle{ }^{6} \mathrm{H}_{5 / 2}|| U^{\lambda} \|\left.\right|^{4} \mathrm{H}_{9 / 2}\right\rangle^{2 a}$ & 0.0001 & 0.0002 & 0.0006 & $\left\langle{ }^{6} \mathrm{H}_{5 / 2}|| S||^{4} G_{5 / 2}^{(1)}\right\rangle=0.78^{b}$ \\
\hline$\left\langle{ }^{6} \mathrm{H}_{5 / 2}|| U^{\lambda} \|\left.\right|^{4} \mathrm{H}_{13 / 2}\right\rangle^{2 a}$ & 0.0 & 0.0 & 0.0002 & $\left\langle{ }^{6} \mathrm{H}_{5 / 2}|| S||^{4} G_{5 / 2}^{(2)}\right\rangle=0.12^{b}$ \\
\hline$\left\langle{ }^{6} \mathrm{H}_{5 / 2}|| U^{\lambda} \|\left.\right|^{4} \mathrm{G}_{9 / 2}\right\rangle^{2 a}$ & 0.0001 & 0.0009 & 0.0013 & $\left\langle{ }^{6} \mathrm{H}_{5 / 2}|| L+2 S||^{4} G_{5 / 2}^{(1)}\right\rangle=1.05^{b}$ \\
\hline$\left\langle{ }^{6} \mathrm{H}_{5 / 2}|| U^{\lambda} \|\left.\right|^{4} \mathrm{I}_{9 / 2}\right\rangle^{2 a}$ & 0.0022 & 0.0005 & 0.0014 & \\
\hline$\left\langle r^{\lambda}\right\rangle$ & $2.73 \times 10^{-17} \mathrm{~cm}^{2}$ & $1.77 \times 10^{-33} \mathrm{~cm}^{4}$ & $2.31 \times 10^{-49} \mathrm{~cm}^{6}$ & \\
\hline
\end{tabular}

${ }^{a}$ Matrix elements of $U^{\lambda}$ for $\mathrm{Sm}^{\mathrm{III}}(\mathrm{aq})$ obtained from ref $31 .{ }^{b}$ Obtained by using the wave functions of $\mathrm{Sm}^{\mathrm{III}}$ in $\mathrm{SmOCl}$.

where $\left\langle r^{\lambda}\right\rangle$ is the radial expectation value of $r^{\lambda}$ for $4 \mathrm{f}$ electrons, $C^{\lambda}$ is a Racah tensor operator, and

$$
F=\frac{1}{\hbar \Delta A_{\mathrm{L}}} \sqrt{\frac{\ln 2}{\pi}} \exp \left[-\left(\frac{\Delta E}{\hbar \Delta A_{\mathrm{L}}}\right)^{2} \ln 2\right]
$$

where $\Delta E$ is the energy difference between the ligand donor level and the lanthanide ion acceptor level and $\Delta A_{\mathrm{L}}$ is the bandwidth at half-height of the ligand state

$$
W_{\mathrm{ET}}^{\mathrm{dp}}=\frac{2 \pi}{\hbar} \frac{e^{2} S_{\mathrm{L}}}{(2 J+1) G R_{\mathrm{L}}^{6}} F \sum_{\lambda} \Omega_{\lambda}^{\text {e.d. }}\left\langle\alpha^{\prime} J^{\prime}\left\|U^{(\lambda)}\right\| \alpha J\right\rangle^{2}
$$

corresponds to the dipole-dipole mechanism $(\lambda=2,4$, and $6)$, and

$$
\begin{aligned}
& W_{\mathrm{ET}}^{\mathrm{ex}}=\frac{8 \pi}{3 \hbar} \frac{e^{2}\left(1-\sigma_{0}\right)^{2}}{(2 J+1) R_{\mathrm{L}}^{4}} F\left\langle\alpha^{\prime} J^{\prime}|| S|| \alpha J\right\rangle^{2} \times \\
& \sum_{m}\left|\left\langle\phi\left|\sum_{k} \mu_{Z}(k) s_{m}(k)\right| \phi^{\prime}\right\rangle\right|^{2}
\end{aligned}
$$

represents the exchange mechanism. In the above equations, $J$ is the total angular momentum quantum number of the rareearth ion and $\alpha$ specifies a $4 \mathrm{f}$ spectroscopic term. $G$ is the degeneracy of the ligand initial state, and $S_{\mathrm{L}}$ is the electric dipole strength associated with the transition $\phi \rightarrow \phi^{\prime}$ in the ligand. The quantities $\langle\||\|\rangle$ are reduced matrix elements of the unit tensor operators $U^{(\lambda)},{ }^{26}$ and $R_{\mathrm{L}}$ is the distance from the rareearth ion nucleus to the region of the ligand molecule in which the ligand donor (or acceptor) state is localized..$^{27}$ In eq $3, S$ is the total spin operator of the rare-earth ion, $\mu_{Z}$ is the $z$ component of the electric dipole operator, $s_{m}(m=0, \pm 1)$ is a spherical component of the spin operator for the ligand electrons, and $\sigma_{0}$ is a distance-dependent screening factor. ${ }^{28}$

The matrix elements $\left\langle\phi\left|\sum_{k} \mu_{Z}(k) s_{m}(k)\right| \phi^{\prime}\right\rangle$ were calculated from the molecular orbital wave functions given by the Sparkle model, ${ }^{29,30}$ which optimizes the coordination geometry and electronic structure of the organic part of the complex. The quantities $\gamma_{\lambda}$ and $F$ were previously described. ${ }^{29}$ The selection rules that can be derived from the above equations are the following: $J+J^{\prime} \geq \lambda \geq\left|J-J^{\prime}\right|$ for the mechanisms expressed by eqs 1 and 2 , and $\Delta J=0, \pm 1$ for the exchange mechanism; in both cases, transitions with $J^{\prime}=J=0$ are excluded. The selection rules for the ligand levels involved can be derived from the electric dipole strength $S_{L}$ and the matrix element of the coupled operators $\mu_{Z}$ and $s_{m}$ in eq 3 .

The normalized populations of the electronic levels, $\eta_{i}$, are described by

$$
\frac{\mathrm{d} \eta_{i}}{\mathrm{~d} t}=-\sum_{\substack{j=1 \\ j \neq i}}^{N} k_{i j} \eta_{i}+\sum_{\substack{j=1 \\ j \neq i}}^{N} k_{\mathrm{ji}} \eta_{j}
$$

where the indices $i$ and $j$ indicate the energy levels involved in the energy transfer process. The $k_{i j}$ or $k_{j i}$ symbols correspond to the decay rate constants between $i$ and $j$ or $j$ and $i$ levels, respectively, and $N$ is the total number of levels involved. In the steady-state regime, all $\mathrm{d} \eta_{i} / \mathrm{d} t$ are equal to zero, and the set of algebraic equations can be solved analytically in terms of the transition and transfer rates. In the present case, the rate equations were solved numerically by using fourth-order Runge-Kutta method with an adaptive integration step. ${ }^{27}$ This set of coupled differential equations belongs to the initial value category, where the populations $\left(\eta_{i}\right)$ at $t=0$ are set equal to 1 for the ground state population and to zero for the other states. The total time of propagation was around $0.01 \mathrm{~s}$, and the initial step size was equal to the inverse of the largest transfer rate constant (approximately $10^{-9} \mathrm{~s}$ ). The numerical solutions of the rate equations yield the time dependence of the energy level populations, which reach the steady-state regime after $10^{-6}$ to $10^{-5} \mathrm{~s}$.

Modeling Energy Transfer Processes in the $\mathrm{Sm}^{\mathrm{III}}$ Helicate. We have applied the above theory for the first time to analyze the energy transfer processes in a $\mathrm{Sm}^{\mathrm{III}}$ compound. The required parameters are listed in Table 1.

The criteria used to determine which of the $\mathrm{Sm}^{\mathrm{III}}$ excited levels could be potentially involved in the ligand-to-metal transfer processes were the following:

1. The energy differences $\Delta E\left({ }^{1} \pi \pi^{*}-\left({ }^{(2 S+1)} \Gamma_{J}\right)\right.$ or $\Delta E\left({ }^{3} \pi \pi^{*}-\right.$ $\left.{ }^{(2 S+1)} \Gamma_{J}\right)$ have been set to $\Delta E \leq \Delta A_{\mathrm{L}} / 2$, to allow for a sufficient spectral overlap integral (Förster's theory); $\Delta A_{\mathrm{L}} / 2$ is around 2200 and $2100 \mathrm{~cm}^{-1}$ for the emission bands corresponding to ${ }^{1} \pi \pi^{*}$ and ${ }^{3} \pi \pi^{*}$ states, respectively. According to this criterion, $\mathrm{Sm}^{\mathrm{III}}$ levels ${ }^{31}$ with energy in the ranges 28100-32500 and 16500$20700 \mathrm{~cm}^{-1}$ only show appropriate resonance conditions and were taken into consideration.

2. In the case of $\mathrm{Sm}^{\mathrm{III}}$, the selection rules derived for multipolar $(\Delta J=2,4,6)$ and exchange $(\Delta J=0, \pm 1)$ mechanisms further restrict the number of levels to 6 and 8 , respectively.

3 . For multipolar mechanisms, only four levels have significant matrix elements $U^{(\lambda)}$ : ${ }^{4} \mathrm{I}_{9 / 2},{ }^{4} \mathrm{H}_{9 / 2},{ }^{4} \mathrm{H}_{13 / 2}$, and ${ }^{4} \mathrm{G}_{9 / 2}$. For the exchange mechanism, only two levels have a reduced matrix element $\left\langle\alpha^{\prime} J^{\prime}|| S|| \alpha J\right\rangle \neq 0:{ }^{4} \mathrm{G}_{5 / 2}{ }^{(1)}$ (ca. $17900 \mathrm{~cm}^{-1}$ ) and ${ }^{4} \mathrm{G}_{5 / 2}{ }^{(2)}$ (ca. $30230 \mathrm{~cm}^{-1}$ ).

\section{Photophysical Properties}

Ligand-Centered Properties. Ligand $\mathrm{L}^{\mathrm{C}}$ is stable in $\mathrm{H}_{2} \mathrm{O}$ and $\mathrm{D}_{2} \mathrm{O}$ solutions and displays three main absorption bands around 48000, 40000, and $32460 \mathrm{~cm}^{-1}$, which are almost $\mathrm{pH}$ insensitive in the range $7-12$. The emission of the singlet state occurs around $25000 \mathrm{~cm}^{-1}$ upon excitation at $38500 \mathrm{~cm}^{-1}$ and the lifetime $\left(\tau_{\mathrm{S}}\right)$ of this emission is $8 \mathrm{~ns}$ (Table 2 ). The quantum yield of uncoordinated $\mathrm{L}^{\mathrm{C}}$, measured at $\mathrm{pH}$ or $\mathrm{pD} 7.5$ and under excitation at $\tilde{v}_{\mathrm{ex}}=29400 \mathrm{~cm}^{-1}$ (Table 2) is 2.4 times larger in $\mathrm{D}_{2} \mathrm{O}(12 \%)$ compared to $\mathrm{H}_{2} \mathrm{O}(5 \%)$, supporting the explanation put forward previously that strong water interaction with the 
TABLE 2: Absolute Quantum Yields $\left(Q_{\mathrm{Abs}} \pm 20 \%\right)$ of the Metal-Centered Luminescence in the $\mathrm{Sm}^{\mathrm{III}}$ and $\mathrm{Yb}^{\mathrm{III}} \mathrm{Helicates}$ of the Ligand-Centered Luminescence for Free and Complexed $\left(\mathrm{L}^{\mathrm{C}}-2 \mathrm{H}\right)^{2-}$ in the $\mathrm{Dy}^{\mathrm{III}}, \mathrm{Sm}^{\mathrm{III}}$, and $\mathrm{Yb}^{\mathrm{III}}$ Helicates, and Lifetimes $(\tau)$ of $\mathrm{Sm}^{\mathrm{III}}$, Y $\mathrm{b}^{\mathrm{III}}$, and $\mathrm{L}^{\mathrm{C}}$, in Solution at $295 \mathrm{~K}$

\begin{tabular}{ccccccc}
\hline compound $^{a}$ & solvent & $c / \mathrm{M}$ & $\tilde{v}_{\text {exd }} / \mathrm{cm}^{-1}$ & $Q^{\mathrm{Ln}}{ }_{\text {abs }} / \%$ & $Q^{\mathrm{L}}$ abs $/ \%$ & $\tau / \mu \mathrm{s}^{b}$ \\
\hline$\left[\mathrm{Sm}_{2}\left(\mathrm{~L}^{\mathrm{c}}-2 \mathrm{H}\right)_{3}\right]$ & $\mathrm{D}_{2} \mathrm{O}$ & $3.1 \times 10^{-6}$ & 27550 & 1.1 & 0.11 & $180 \pm 1$ \\
& $\mathrm{H}_{2} \mathrm{O}$ & $4.0 \times 10^{-6}$ & 27550 & 0.14 & 0.03 & $42.0 \pm 0.4$ \\
{$\left[\mathrm{Yb}_{2}\left(\mathrm{~L}^{\mathrm{c}}-2 \mathrm{H}\right)_{3}\right]$} & $\mathrm{D}_{2} \mathrm{O}$ & $5.1 \times 10^{-6}$ & 32250 & 1.8 & 0.20 & $40 \pm 2$ \\
{$\left[\mathrm{Dy}_{2}\left(\mathrm{~L}^{\mathrm{c}}-2 \mathrm{H}\right)_{3}\right]$} & $\mathrm{D}_{2} \mathrm{O}$ & $2.0 \times 10^{-6}$ & 26700 & -- & 0.18 & -- \\
& $\mathrm{H}_{2} \mathrm{O}$ & $1.1 \times 10^{-6}$ & 27000 & -- & 0.08 & -- \\
$\mathrm{L}^{\mathrm{c}}$ & $\mathrm{D}_{2} \mathrm{O}$ & $8.8 \times 10^{-7}$ & 29410 & - & 12 & $0.008 \pm 0.0006$ \\
& $\mathrm{H}_{2} \mathrm{O}$ & $8.0 \times 10^{-7}$ & 29410 & -- & $5.0^{c}$ & --
\end{tabular}

${ }^{a}$ At $\mathrm{pH}$ or $\mathrm{pD}$ 7.5. ${ }^{b}$ Obtained monitoring the $\mathrm{Sm}\left({ }^{4} \mathrm{G}_{5 / 2} \rightarrow{ }^{6} \mathrm{H}_{7 / 2}\right)$ transition, the ${ }^{1} \pi \pi^{*}$ ligand emission, and the $\mathrm{Yb}\left({ }^{2} \mathrm{~F}_{5 / 2} \rightarrow{ }^{2} \mathrm{~F}_{7 / 2}\right)$ transition. ${ }^{c}$ As compared to $5.5 \%$ reported in ref 11 .

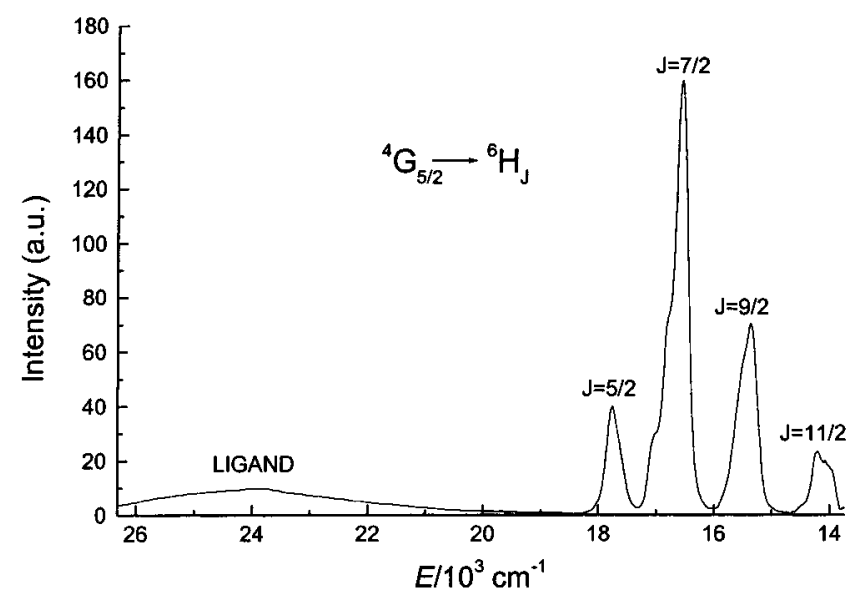

Figure 1. Emission spectrum of the $\left[\mathrm{Sm}_{2}\left(\mathrm{~L}^{\mathrm{C}}-2 \mathrm{H}\right)_{3}\right]$ in $\mathrm{D}_{2} \mathrm{O}$ upon excitation at $27250 \mathrm{~cm}^{-1}$, at $295 \mathrm{~K}$ and $\mathrm{pD}=7.5$.

carboxylic groups contributes to luminescence quenching in $\mathrm{H}_{2} \mathrm{O} .{ }^{11}$

Upon formation of the $\left[\mathrm{Ln}_{2}\left(\mathrm{~L}^{\mathrm{C}}-2 \mathrm{H}\right)_{3}\right]$ helicates, the lowerenergy $\pi \rightarrow \pi^{*}$ transition of the $\left[\mathrm{L}^{\mathrm{C}}-2 \mathrm{H}\right]^{2-}$ moieties undergoes a red shift of $2400 \mathrm{~cm}^{-1}$ with the appearance of a shoulder on its high-energy side, while the absorption band of the higher energy transition occurs around $50000 \mathrm{~cm}^{-1}$. Weak ligandcentered luminescence is seen for all the helicates, centered around $24000 \mathrm{~cm}^{-1}$ and with a quantum yield about 2 orders of magnitude smaller compared to that of the free ligand. For $\mathrm{Nd}^{\mathrm{III}}, \mathrm{Sm}^{\mathrm{III}}$, and $\mathrm{Yb}^{\mathrm{III}}$, metal-centered luminescence occurs as well; it is extremely weak for $\mathrm{Nd}^{\mathrm{III}}$ but is not observed at all for Dy ${ }^{I I I}$. Given that the triplet state emission from the ligand at $77 \mathrm{~K}$ is also much weaker in the Dy ${ }^{\mathrm{III}}$ helicate than in the free ligand while no metal-centered luminescence is seen, we conclude that energy transfer does occur from the ligand to the Dy ${ }^{\mathrm{III}}$ ion, but that the energy is then dissipated through nonradiative processes. A similar explanation is valid for the $\mathrm{Nd}^{\mathrm{III}}$ helicate. These two compounds were not further investigated in view of their poor luminescent properties.

Metal-Centered Photophysical Properties. The emission spectrum of the $\mathrm{Sm}^{\mathrm{III}}$ helicate is reported in Figure 1. It displays four main bands at 17762, 16584, 15361, and $14205 \mathrm{~cm}^{-1}$, corresponding to the ${ }^{4} \mathrm{G}_{5 / 2} \rightarrow{ }^{6} \mathrm{H}_{5 / 2},{ }^{4} \mathrm{G}_{5 / 2} \rightarrow{ }^{6} \mathrm{H}_{7 / 2},{ }^{4} \mathrm{G}_{5 / 2} \rightarrow{ }^{6} \mathrm{H}_{9 / 2}$, and ${ }^{4} \mathrm{G}_{5 / 2} \rightarrow{ }^{6} \mathrm{H}_{11 / 2}$ transitions, respectively, in addition to the weak fluorescence band from the ligand at $23810 \mathrm{~cm}^{-1}$. The ratio of the emission intensities as measured by the band areas, $I\left({ }^{4} \mathrm{G}_{5 / 2} \rightarrow{ }^{6} \mathrm{H}_{J}\right) / I\left({ }^{1} \pi \pi^{*}\right)$ amounts to 2.3 in $\mathrm{D}_{2} \mathrm{O}$. The quantum yield of the ${ }^{1} \pi \pi^{*}$ emission in $\left[\mathrm{Sm}_{2}\left(\mathrm{~L}^{\mathrm{C}}-2 \mathrm{H}\right)_{3}\right]$ is $110\left(\mathrm{D}_{2} \mathrm{O}\right)$ and 170 $\left(\mathrm{H}_{2} \mathrm{O}\right)$ times smaller compared to uncoordinated $\left(\mathrm{L}^{\mathrm{C}}-2 \mathrm{H}\right)^{2-}$. On the other hand, we have determined the quantum yield of the metal-centered luminescence at $\mathrm{pH} 7.5$, under excitation at $27550 \mathrm{~cm}^{-1}$. Three different standards were used, leading to very similar values with averages of $1.1 \%$ in $\mathrm{D}_{2} \mathrm{O}$ and $0.14 \%$ in $\mathrm{H}_{2} \mathrm{O}$ (6 determinations). In summary, and roughly speaking, complexation of the $\mathrm{Sm}^{\mathrm{III}}$ ion results in more than $99 \%$ of the energy of the excited ligand state being transferred onto the metal ion; on the other hand, only a very small part is emitted in a radiative way by $\mathrm{Sm}^{\mathrm{III}}$.

It is noteworthy that the quantum yields determined can be considered as being relatively large for a $\mathrm{Sm}^{\mathrm{III}}$-containing compound: the energy gap between the lowest sublevel of ${ }^{5} \mathrm{G}_{5 / 2}{ }^{(1)}$ and the highest sublevel of the ${ }^{6} \mathrm{~F}$ multiplet, ${ }^{6} \mathrm{~F}_{11 / 2}$, is known to be around $7400 \mathrm{~cm}^{-1}$, which favors nonradiative deexcitation processes, especially in compounds with organic ligands possessing several vibrations of relatively high energy. As a comparison, a quantum yield of $0.20 \%$ in water has been reported for the $\mathrm{Sm}^{\mathrm{III}}$ complex with a pyrazole-containing ligand, $N, N, N^{\prime}, N^{\prime}$-\{2,6-bis[3-(aminomethyl)pyrazol-1-yl]pyrazine\}tetrakis(acetic acid), $\mathrm{L}^{1},{ }^{32}$ which displays good chromophoric and energy transfer properties, while a quantum yield of $2 \%$ has been reported for an especially well protected micellar system suitable for fluoroimmunoassays and containing 1,1,1-trifluoro4-(2-naphthyl)-butane-2,4-dione, trioctylphosphine oxide and Triton X-100. ${ }^{4}$

The lifetime of the ${ }^{4} \mathrm{G}_{5 / 2}^{(1)}$ level increases from 42 to $180 \mu \mathrm{s}$ in going from $\mathrm{H}_{2} \mathrm{O}$ to $\mathrm{D}_{2} \mathrm{O}$. Using Kimura's equation, ${ }^{33}$ we calculate that essentially no water is bound into the first coordination sphere, in line with previous observations for the $\mathrm{Eu}^{\mathrm{III}}$ and $\mathrm{Tb}^{\mathrm{III}}$ helicates. ${ }^{11}$ Therefore, the large effect of $\mathrm{H}_{2} \mathrm{O}$ on the radiative rate constant is due to second-sphere interactions. The lifetime of $180 \mu \mathrm{s}$ in $\mathrm{D}_{2} \mathrm{O}$ is long, compared with ${ }^{4} \mathrm{G}_{5 / 2}^{(1)}$ lifetimes reported previously: 79-96 $\mu$ s in several systems used for fluoroimmunoassays and containing a $\beta$-diketonate, Triton X-100 and YIII as co-luminescence enhancement ion, ${ }^{34} 86 \mu$ s for $\mathrm{Sm}^{\text {III }}$ chelated by 2 -naphthoyltrifluoroacetone in benzene ${ }^{35}$, and $30 \mu$ s for the complex with ligand $L^{1}{ }^{32}$

A relatively intense metal-centered NIR emission is observed for the $\mathrm{Yb}^{\mathrm{III}}$ helicate in $\mathrm{D}_{2} \mathrm{O}$ upon excitation at $32258 \mathrm{~cm}^{-1}$, while it is extremely weak in $\mathrm{H}_{2} \mathrm{O}$, which prevented us to measure the corresponding lifetime. The spectrum is depicted in Figure 2. It displays a band centered at ca. $10000 \mathrm{~cm}^{-1}$ with four main components at $10493\left(2^{\prime}-0\right), 10224\left(0^{\prime}-0\right), 10091$ $\left(0^{\prime}-2\right)$, and $9852\left(0^{\prime}-3\right) \mathrm{cm}^{-1}$, assigned to the ${ }^{2} \mathrm{~F}_{5 / 2} \rightarrow{ }^{2} \mathrm{~F}_{7 / 2}$ transitions. They arise from the $M_{J}$ splitting of the emitting and/ or fundamental state, as a consequence of ligand field effects. The line at $10224 \mathrm{~cm}^{-1}$ corresponds to the lowest component of ${ }^{2} \mathrm{~F}_{5 / 2}$, since at this wavelength the excitation and emission lines overlap. Excitation spectrum in the infrared region of the $\mathrm{Yb}^{\mathrm{III}}$ helicate, recorded by monitoring the emission from $\mathrm{Yb}^{\mathrm{III}}$ at $10200 \mathrm{~cm}^{-1}$, presents three very weak bands centered at 10500, 10800, and $11110 \mathrm{~cm}^{-1}$ (right side of Figure 2, see scale). Only the first one is of electronic nature, the latter two being of vibronic origin. The total ligand-field splitting amounts 


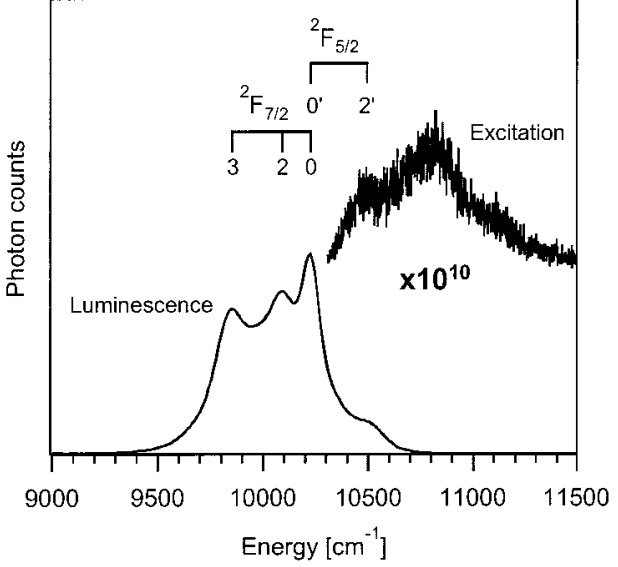

Figure 2. Spectra of $\left[\mathrm{Yb}_{2}\left(\mathrm{~L}^{\mathrm{C}}-2 \mathrm{H}\right)_{3}\right]$ in $\mathrm{D}_{2} \mathrm{O}$. Left: emission spectrum at $295 \mathrm{~K}$ and $\mathrm{pD}=7.5$ upon excitation at $32258 \mathrm{~cm}^{-1}$. Right: excitation spectrum obtained by analyzing the infrared emission at $10200 \mathrm{~cm}^{-1}$, at $15 \mathrm{~K}$ and $\mathrm{pD}=7.5$. The level numbering refers to the emission spectrum.

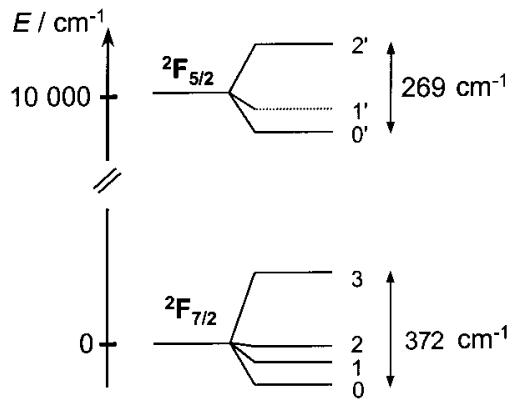

Figure 3. Ligand-field sublevels of $\mathrm{Yb}^{\mathrm{III}}$ in $\left[\mathrm{Yb}_{2}\left(\mathrm{~L}^{\mathrm{C}}-2 \mathrm{H}\right)_{3}\right]$, as determined from emission and excitation spectra at 295 and $15 \mathrm{~K}$, respectively. Level $1^{\prime}\left({ }^{2} \mathrm{~F}_{5 / 2}\right)$ has not been formally identified.

to 269 and $372 \mathrm{~cm}^{-1}$ for the ${ }^{2} \mathrm{~F}_{5 / 2}$ and ${ }^{2} \mathrm{~F}_{7 / 2}$ levels, respectively (Figure 3). Analyzing these splittings in terms of group theory allowed us to assess the site symmetry of the $\mathrm{Yb}^{\mathrm{III}}$ ions, which is consistent with $D_{3}$. Determination of the irreducible representations of the angular momentum operator $J$ in this symmetry leads to four sublevels $\left(3 \mathrm{E}_{1 / 2}+\mathrm{E}_{3 / 2}\right)$ for ${ }^{2} \mathrm{~F}_{7 / 2}$ and three sublevels $\left(2 \mathrm{E}_{1 / 2}+\mathrm{E}_{3 / 2}\right)$ for ${ }^{2} \mathrm{~F}_{5 / 2}$. This is in agreement with the number of experimentally determined sublevels, with paramagnetic NMR measurements indicating that the helicates retain timeaveraged $D_{3}$ symmetry along the entire $\mathrm{Ln}^{\mathrm{III}}$ series, ${ }^{36}$ and with the X-ray crystal structure of the $\mathrm{Yb}^{\mathrm{III}}$ helicate. ${ }^{11} \mathrm{Up}$-conversion processes have been evidenced in $\mathrm{Yb}$ dimers in nonmolecular ionic lattices. ${ }^{37}$ To investigate whether such a process takes place in the $\mathrm{Yb}^{\mathrm{III}}$ helicate, we have recorded its emission spectrum upon direct metal excitation in the infrared region, at $\tilde{v}_{\text {exc }}=$ $10753 \mathrm{~cm}^{-1}$, but no visible emission was observed. A definitive conclusion cannot, however, be drawn from this experiment: in ionic systems, the photon ratio between visible and NIR emission is around $10^{-6,37}$ and if it does exist, we expect a less efficient up-conversion process in the dimetallic helicate in view of the large $\mathrm{Yb}^{\mathrm{III}}-\mathrm{Yb}^{\mathrm{III}}$ separation $\left(9.1-9.3 \AA^{11}\right)$ so that an extremely faint signal would be expected. On the other hand, direct metal excitation leads to a very weak $\mathrm{Yb}^{\mathrm{III}}$-centered emission, compared with ligand excitation, in line with the very weak excitation spectrum shown on Figure 2. This points to an appreciable sensitization of the $\mathrm{Yb}^{\mathrm{III}}$ by the ligand, as shown by the following data.

The lifetime of the $\mathrm{Yb}\left({ }^{2} \mathrm{~F}_{5 / 2}\right)$ state is long in $\mathrm{D}_{2} \mathrm{O}, 40 \mu$ s (Table 2) compared to solution data reported previously, e.g., $18.6 \mu \mathrm{s}$ in $\mathrm{DMSO}-\mathrm{d}_{6}$ for a $m$-terphenyl-based complex bearing a

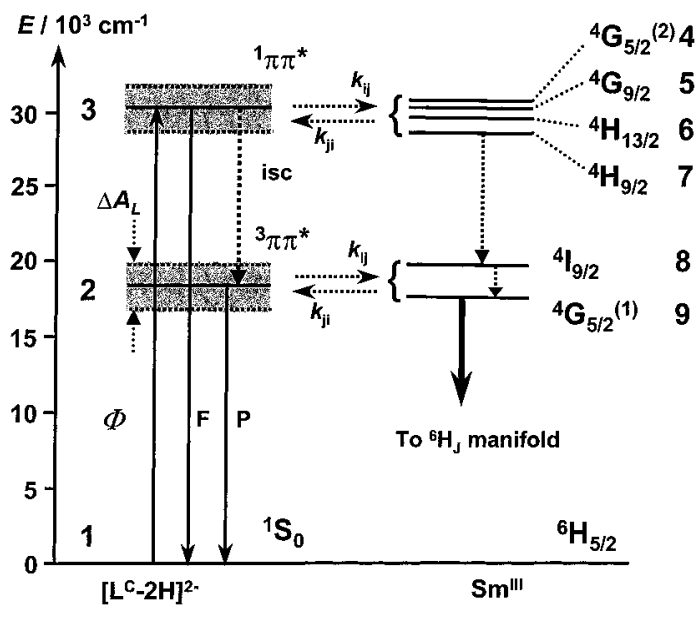

Figure 4. Schematic and partial diagram of the main energy transfer processes in $\left[\mathrm{Sm}_{2}\left(\mathrm{~L}^{\mathrm{C}}-2 \mathrm{H}\right)_{3}\right]$. The solid and dashed arrows represent radiative and nonradiative processes, respectively. Key: F, fluorescence; $\mathrm{P}$, Phosphorescence; isc, intersystem crossing; $\Phi$, photon flux; $\Delta A_{\mathrm{L}}$, see eq $1 b$.

triphenylene chromophore ${ }^{38}$ and $6.2 \mu$ s in $\mathrm{D}_{2} \mathrm{O}$ for a complex with a chiral macrocyclic tetra-amide ${ }^{39}$ As a result, the quantum yield of the metal-centered luminescence amounts to $1.8 \%\left(\mathrm{D}_{2} \mathrm{O}\right)$ upon ligand excitation which, again is fairly large compared with the values reported in the literature for other $\mathrm{Yb}^{\text {III }}$ complexes, e.g., $0.45 \%$ for the complex with fluorexon in $\mathrm{D}_{2} \mathrm{O}^{40}$ or $0.5 \%$ for a terphenyl-based complex in DMSO. ${ }^{41}$

The metal-centered emission quantum yields for the $\mathrm{Sm}^{\mathrm{III}}$ and $\mathrm{Yb}^{\mathrm{III}}$ helicates are large, compared to literature data, despite their absolute low values. Usually the nonradiative de-excitation of the metal-ion emitter level is related to the energy gap between the lowest luminescent excite state and the highest sublevel of the ground multiplet. These gaps amount to $\sim 7400$ $\mathrm{cm}^{-1}$ for the ${ }^{4} \mathrm{G}_{5 / 2} \rightarrow{ }^{6} \mathrm{~F}_{11 / 2}$ transition of $\mathrm{Sm}^{\mathrm{III}}$ and to $\sim 10200$ $\mathrm{cm}^{-1}$ for the ${ }^{2} \mathrm{~F}_{5 / 2} \rightarrow{ }^{2} \mathrm{~F}_{7 / 2}$ transition of $\mathrm{Yb}^{\mathrm{III}}$. ${ }^{42}$ Therefore, overtones and/or combinations of high-energy vibrational modes, such as $\mathrm{C}-\mathrm{H}$ and $\mathrm{C}=\mathrm{O}$ oscillators, are in principle able to match these gaps, resulting in efficient quenching of the luminescent states. Such quenching mechanisms appear however to be not very efficient in the studied helicates given that the lifetimes, which are among the largest reported for $\mathrm{Sm}^{\text {III }} 33-35$ and $\mathrm{Yb}^{\text {III }}$ compounds, are quite longer in $\mathrm{D}_{2} \mathrm{O}$ compared to $\mathrm{H}_{2} \mathrm{O}$. This can be traced back to the rigidity of the coordination environment in these molecular dimetallic edifices.

\section{Modeling of the Energy Transfer Processes}

We have attempted to rationalize the quantitative data described above for $\mathrm{Sm}^{\mathrm{III}}$ and $\mathrm{Yb}^{\mathrm{III}}$ by an adequate modeling. The diagram sketched in Figure 4 shows the energy transfer processes taken into consideration for the sensitization of the Sm ${ }^{\text {III }}$ compound. This model is based on the observed photophysical properties of this helicate and allows ligand-to-metal energy transfers to occur through either the singlet or triplet state. The initial excitation takes place through UV absorption by the lower energy singlet state of the $\left(\mathrm{L}^{\mathrm{C}}-2 \mathrm{H}\right)^{2-}$ moieties. The second singlet state, around $50000 \mathrm{~cm}^{-1}$ (Table 3), was not taken into consideration, since experimental quantum yield were determined upon excitation around $28000 \mathrm{~cm}^{-1}$. The singlet state is then deactivated by three main paths: (i) decay to the ground state (radiative and nonradiative), (ii) intersystem crossing to the triplet state, followed either by transfer onto the metal ion or by decay to the ground state, and (iii) energy transfer to high energy level(s) of the lanthanide ion. The second 
TABLE 3: Experimental Transition Energies $\left(\mathrm{cm}^{-1}\right)$ from and to the Singlet and Triplet States of $\left[\operatorname{Ln}_{2}\left(\mathrm{~L}^{\mathrm{c}}-\mathbf{2 H}\right)_{3}\right]$

\begin{tabular}{cll}
\hline triplet state $^{a}$ & \multicolumn{2}{c}{ singlet state $^{b}$} \\
\cline { 2 - 3 } $\mathrm{Ln}=\mathrm{Gd}$ & $\mathrm{Ln}=\mathrm{Sm}$ & $\mathrm{Ln}=\mathrm{Yb}$ \\
\hline 16560 & $28490 \mathrm{sh}$ & $28460 \mathrm{sh}$ \\
17950 & 30300 & 30380 \\
19340 & $34600 \mathrm{sh}$ & $34550 \mathrm{sh}$ \\
20660 & $40065 \mathrm{sh}$ & $40000 \mathrm{sh}$ \\
& 50000 & 50250
\end{tabular}

${ }^{a}$ From phosphorescence spectra at $10 \mathrm{~K}$ for Gd helicate, obtained from ref 11. ${ }^{b}$ From absorption spectra in $\mathrm{H}_{2} \mathrm{O}$ at $293 \mathrm{~K}$; $\mathrm{sh}=$ shoulder.

process is important for lanthanide containing compounds because intersystem crossing rates (isc) are enhanced by paramagnetic and heavy atom effects. ${ }^{43}$ This is exemplified by the quantum yield of the ligand-centered fluorescence of the $\mathrm{Gd}^{\mathrm{III}}$ helicate in $\mathrm{H}_{2} \mathrm{O}$ which amounts to only $0.93 \%,{ }^{11}$ down from $5 \%$ for the free ligand. A similar, but much more pronounced trend is observed for the $\mathrm{Sm}^{\mathrm{III}}$ helicate that presents a very small quantum yield in $\mathrm{D}_{2} \mathrm{O}, 0.03 \%$, compared to $12 \%$ for the free ligand. These data point to the intersystem crossing in the ligand increasing upon complexation with a concomitant energy transfer onto the metal ion and a large decrease in the emission from the singlet state.

The $\mathrm{Sm}^{\mathrm{III}}$ ion possesses a wealth of electronic levels, which have been identified and labeled by Carnall et al. ${ }^{31}$ We have used several criteria to select the levels most amenable to energy transfer, in particular resonance conditions and selection rules (see Experimental Section), which limited the number of potentially interesting levels to six: (i) an exchange mechanism is operative for the two ${ }^{4} \mathrm{G}_{5 / 2}$ levels (30230 and $17900 \mathrm{~cm}^{-1}$ ), and multipolar mechanisms are effective for the ${ }^{4} \mathrm{I}_{9 / 2},{ }^{4} \mathrm{H}_{9 / 2},{ }^{4} \mathrm{H}_{13 / 2}$, and ${ }^{4} \mathrm{G}_{9 / 2}$ levels. To apply the selection rules, we have considered solely the ground state ${ }^{6} \mathrm{H}_{5 / 2}$; at room temperature, population of the ${ }^{6} \mathrm{H}_{7 / 2}$ level is around $0.06 \%$ only, and we think that the benefit introduced by taking the latter level into consideration would have been largely outbalanced by the severe complications brought in the model.

The parameters used in the calculation of the energy transfer rate constants and quantum yield were the following: $A_{\mathrm{T}}$ (spontaneous emission coefficient $)=880 \mathrm{~s}^{-1}$ and $1 / \tau=23998$ $\mathrm{s}^{-1}$ in $\mathrm{H}_{2} \mathrm{O}$, and $A_{\mathrm{T}}=894 \mathrm{~s}^{-1}$ and $1 / \tau=5531 \mathrm{~s}^{-1}$ in $\mathrm{D}_{2} \mathrm{O}$. The ${ }^{4} \mathrm{G}_{5 / 2} \rightarrow{ }^{6} \mathrm{H}_{5 / 2}$ transition was taken as reference in the estimate of the spontaneous emission coefficient because the quantities $U^{(\lambda)}$ are very small for this transition. The $R_{\mathrm{L}}$ and $\langle\phi| \sum_{k} \mu_{Z}(k)$ $s_{m}(k)\left|\phi^{\prime}\right\rangle$ values have been calculated previously for the following compounds: $\left[\mathrm{Eu}\left(\mathrm{NO}_{3}\right)_{3} \mathrm{~L}(\mathrm{MeOH})\right],{ }^{14} \mathrm{Eu}(\mathrm{TTA})_{3} \cdot 2 \mathrm{H}_{2} \mathrm{O}$ and $\mathrm{Eu}(\mathrm{TTA})_{3} \cdot 2 \mathrm{DBSO},{ }^{29}$ where $\mathrm{L}=2,6$-bis $(1$-methylbenzimidazol-2-yl)pyridine, TTA $=$ thenoyltrifluoroacetonate and DBSO $=$ dibenzyl sulfoxide. In these compounds, $R_{\mathrm{L}}$ ranges between 4.3 and $4.5 \AA$ and $\left\langle\phi\left|\sum_{k} \mu_{\mathrm{Z}}(k) s_{m}(k)\right| \phi^{\prime}\right\rangle$ between $0.8 \times 10^{-36}$ and $1.9 \times 10^{-36} \mathrm{esu}^{2} \mathrm{~cm}^{2}$. In view of their relative insensitivity to the nature of the complex, we have chosen the same values as those calculated by the Sparkle model for $\left[\mathrm{Eu}\left(\mathrm{NO}_{3}\right)_{3} \mathrm{~L}(\mathrm{MeOH})\right]$, $4.3 \AA$ and $1.9 \times 10^{-36} \mathrm{esu}^{2} \mathrm{~cm}^{2}$, respectively. ${ }^{14}$ The other parameters were set to $\Delta A_{\mathrm{L}}\left({ }^{3} \pi \pi^{*}\right)=4200 \mathrm{~cm}^{-1}$, from the phosphorescence spectra of the $\mathrm{Gd}^{\mathrm{III}}$ helicate, ${ }^{11} \Delta A_{\mathrm{L}}\left({ }^{1} \pi \pi^{*}\right)=$ $4400 \mathrm{~cm}^{-1}$, from the absorption band of the lower energy singlet centered at $30300 \mathrm{~cm}^{-1}$, and $\sigma_{0}=0.99$, from the structural data reported for the $\mathrm{Eu}^{\mathrm{III}}$ and $\mathrm{Tb}^{\mathrm{III}}$ helicates. ${ }^{11}$ The transfer rate constant $k_{13}=\phi=10^{4} \mathrm{~s}^{-1}$ was assumed to be identical with those found for other coordination compounds, ${ }^{7}$ while the rate constants for nonradiative decays from the excited $\mathrm{Sm}^{\mathrm{III}}$ levels have been set to $10^{6} \mathrm{~s}^{-1}$. $^{44}$
TABLE 4: Calculated Energy Transfer Rates $\left(\mathrm{s}^{-1}\right)$ for $\left[\mathrm{Sm}_{2}\left(\mathbf{L}^{\mathbf{c}}-\mathbf{2 H}\right)_{3}\right]$

\begin{tabular}{ccccc}
\hline $\begin{array}{c}E\left(\mathrm{~L}^{\mathrm{C}} \text { state }\right) / \\
\mathrm{cm}^{-1}\end{array}$ & $\begin{array}{c}E(4 \mathrm{f} \text { state }) / \\
\mathrm{cm}^{-1}\end{array}$ & $\begin{array}{c}\text { transfer rate } \\
W_{\mathrm{ET}} / \mathrm{s}^{-1}\end{array}$ & $\begin{array}{c}\text { back-transfer rate } \\
W_{\mathrm{BT}} / \mathrm{s}^{-1}\end{array}$ \\
\hline${ }^{3} \pi \pi^{*}(18620)$ & $\rightarrow$ & ${ }^{4} \mathrm{G}_{5 / 2}^{(1)}(17900)$ & $8.4 \times 10^{9}$ & $2.72 \times 10^{8}$ \\
${ }^{3} \pi \pi^{3}(18620)$ & $\rightarrow$ & ${ }^{4} \mathrm{I}_{9 / 2}(20500)$ & $4.67 \times 10^{6}$ & 601 \\
${ }^{1} \pi \pi^{*}(30300)$ & $\rightarrow$ & ${ }^{4} \mathrm{H}_{9 / 2}(29000)$ & $6.0 \times 10^{5}$ & $1.23 \times 10^{3}$ \\
${ }^{1} \pi \pi^{2}(30300)$ & $\rightarrow$ & ${ }^{4} \mathrm{H}_{13 / 2}(29800)$ & $1.37 \times 10^{5}$ & $1.27 \times 10^{4}$ \\
${ }^{1} \pi \pi^{*}(30300)$ & $\rightarrow$ & ${ }^{4} \mathrm{G}_{9 / 2}(30100)$ & $1.52 \times 10^{6}$ & $5.87 \times 10^{5}$ \\
${ }^{1} \pi \pi^{2}(30300)$ & $\rightarrow$ & ${ }^{4} \mathrm{G}_{5 / 2}^{(2)}(30232)$ & $1.75 \times 10^{8}$ & $1.27 \times 10^{8}$
\end{tabular}

TABLE 5: Calculated Quantum Yield (\%) of $\left[\mathrm{Sm}_{2}\left(\mathrm{~L}^{\mathrm{c}}-2 \mathrm{H}\right)_{3}\right]$ at $300 \mathrm{~K}$ for Several Values of the Transition Rates $^{a}$

\begin{tabular}{cccll}
\hline$k_{31}\left(\mathrm{~s}^{-1}\right)$ & $k_{21}\left(\mathrm{~s}^{-1}\right)$ & $k_{32}\left(\mathrm{~s}^{-1}\right)$ & $Q\left(\mathrm{D}_{2} \mathrm{O}\right)$ & $Q\left(\mathrm{H}_{2} \mathrm{O}\right)$ \\
\hline $10^{5}$ & $10^{7}$ & $10^{8}$ & 0.271 & 0.253 \\
$10^{6}$ & $10^{7}$ & $10^{8}$ & 0.27 & 0.25 \\
$10^{7}$ & $10^{7}$ & $10^{8}$ & 0.25 & 0.23 \\
$10^{8}$ & $10^{7}$ & $10^{8}$ & 0.14 & 0.12 \\
$10^{9}$ & $10^{7}$ & $10^{8}$ & 0.025 & 0.024 \\
$10^{8}$ & $10^{5}$ & $10^{8}$ & 5.2 & 1.6 \\
$10^{8}$ & $10^{6}$ & $10^{8}$ & 1.2 & 0.79 \\
$10^{8}$ & $10^{8}$ & $10^{8}$ & 0.013 & 0.014 \\
$10^{8}$ & $10^{9}$ & $10^{8}$ & 0.0014 & 0.0014 \\
$10^{8}$ & $10^{7}$ & $10^{5}$ & 0.0070 & 0.0065 \\
$10^{8}$ & $10^{7}$ & $10^{6}$ & 0.0093 & 0.0086 \\
$10^{8}$ & $10^{7}$ & $10^{7}$ & 0.030 & 0.028 \\
$10^{8}$ & $10^{7}$ & $10^{9}$ & 0.25 & 0.23 \\
& & & & \\
& experimental data & & 1.1 & 0.14
\end{tabular}

${ }^{a}$ See Figure 4 for the numbering of the states and, therefore, the labeling of the rate constants. Italicized values reproduce best the experimental data.

The theoretical values for the forward and back-transfer rate constants calculated from eqs $1-3$ are listed in Table 4 . They vary widely for the different levels involved, between $10^{5}$ and $10^{9} \mathrm{~s}^{-1}$, a range comparable to that found for the transfer rate constants in the $1: 1$ and 1:3 complexes of $\mathrm{Eu}^{\mathrm{III}}$ with L. ${ }^{45}$ The largest rate constants correspond to both ${ }^{4} \mathrm{G}_{5 / 2}$ levels and a first conclusion is that these levels are implicated in the main path(s) of the energy transfer process. The numerical solutions of the rate equations were used to calculate the populations of the levels (eq 4) which, in turn, were used to estimate the emission quantum yields.

We have performed a variable analysis to investigate the dependence of the quantum yield upon the rate constants $k_{21}$, $k_{31}$, and $k_{32}$ (Table 5). A quite satisfactory match between the calculated $(1.2 \%)$ and experimental $(1.1 \%)$ quantum yields in $\mathrm{D}_{2} \mathrm{O}$ solution was found by setting $k_{21}=10^{6} \mathrm{~s}^{-1}, k_{31}=10^{8}$ $\mathrm{s}^{-1}$, and $k_{32}=10^{8} \mathrm{~s}^{-1}$. For $\mathrm{H}_{2} \mathrm{O}$ solution, $k_{21}=10^{7} \mathrm{~s}^{-1}, k_{31}=$ $10^{8} \mathrm{~s}^{-1}$, and $k_{32}=10^{8} \mathrm{~s}^{-1}$ gave a calculated quantum yield $=$ $0.12 \%$, as compared to $0.14 \%$ for the experimental one. It is noteworthy that, as expected, the only rate constant influenced by the solvent change is $k_{21}$, which becomes 10 times larger in $\mathrm{H}_{2} \mathrm{O}$ compared to that in $\mathrm{D}_{2} \mathrm{O}$, while the intersystem crossing rate constant remains the same $\left(10^{8} \mathrm{~s}^{-1}\right)$ and is comparable to that found in the complexes with $\mathrm{L}\left(10^{7}-10^{8} \mathrm{~s}^{-1}\right)^{45}$ and in metallotexaphyrins containing coordinated $\mathrm{Nd}^{\mathrm{III}}$ and $\mathrm{Y}^{\mathrm{III}}$ ions. ${ }^{46}$ This means that second sphere interactions of water molecules with the carboxylic groups not only depopulate the emitter level of the $\mathrm{Sm}^{\mathrm{III}}$ ion, but also the triplet state level, consistent with the quantum yields for the ligand-centered luminescence discussed above. The large $k_{32}$ value is typical of a heavy-atom effect. $^{43}$

The lifetime of the ${ }^{1} \pi \pi^{*}$ emission in the helicate depends on the energy transfer rate constants to the $\mathrm{Sm}^{\mathrm{III}}$ upper excited 
levels, on $k_{32}$, and on the internal conversion rate constant $k_{31}$. The same lifetime in the uncoordinated ligand depends only on $k_{31}$ and $k_{32}$, and the latter rate constant is smaller in the ligand than in the complex, as describe above. Therefore, the internal conversion rate constant $k_{31}$ in the $\mathrm{Sm}^{\mathrm{III}}$ helicate should be comparable to the inverse of the singlet emission lifetime (1/ $\tau_{\mathrm{S}}$ ) in the uncoordinated ligand, which is the case: $1 / \tau_{\mathrm{S}}=1.2$ $\times 10^{8} \mathrm{~s}^{-1}$ compares well with the $k_{31}$ value of $10^{8} \mathrm{~s}^{-1}$ reproducing best the experimental quantum yields in both water and deuterated water.

Finally, we have evaluated the contributions of the various energy-transfer processes to the overall quantum yield by performing the theoretical calculations for each separate level. It turns out that ${ }^{3} \pi \pi^{*} \rightarrow{ }^{4} \mathrm{G}_{5 / 2}{ }^{(1)}$ accounts for ca. $97.5 \%$ of the total energy transfer while ${ }^{1} \pi \pi^{*} \rightarrow{ }^{4} \mathrm{G}_{5 / 2}(2)$ accounts for $1 \%$ and all the other processes for the remaining $1.5 \%$. Therefore, the common, and simplified, thinking that ligand-to-metal energy transfers in lanthanide-containing compounds goes essentially through the triplet state is validated in our particular case. One difference is that the main operative mechanism is an exchange one and not a Förster-type mechanism, pointing to some orbital overlap between the ligand and $4 \mathrm{f}$ states.

The $\mathrm{Yb}^{\mathrm{III}}$ helicate in $\mathrm{D}_{2} \mathrm{O}$ presents a much stronger metalcentered emission in the infrared upon ligand excitation than upon direct excitation of the metal ion, clearly establishing the sensitizing role of the ligand. The oxygen effect on the sensitized luminescence intensity and time-resolved luminescence were investigated with the objective of determining which energy transfer mechanism is operative in this compound, since there is very little overlap between the ligand ${ }^{1} \pi \pi^{*}$ and ${ }^{3} \pi \pi^{*}$ states and the ${ }^{2} \mathrm{~F}_{5 / 2}$ level. Oxygen may deactivate the triplet level, and if the main path of the ligand-to-metal energy transfer goes through the ${ }^{3} \pi \pi^{*}$ level, this is reflected in a concomitant decrease in the lanthanide-centered emission. The emission spectra of the $\mathrm{Yb}^{\mathrm{III}}$ helicate were therefore measured for both deaerated and nondegassed solutions and they did not show significant intensity change. The rate constant of oxygen quenching of the triplet state $\left(k_{\mathrm{Ox}}\right)$ is equal to the product of the diffusion-controlled quenching rate constant by the oxygen concentration, $k_{\mathrm{ox}}=k_{\text {diff }}\left[\mathrm{O}_{2}\right]$. In $\mathrm{D}_{2} \mathrm{O},\left[\mathrm{O}_{2}\right]=0.265 \mathrm{mM}^{47}$ and $k_{\text {diff }}$ is on the order of $10^{10} \mathrm{M}^{-1} \mathrm{~s}^{-1,38}$ therefore, $k_{\mathrm{ox}}=2.7 \times$ $10^{6} \mathrm{~s}^{-1}$. Since oxygen has no effect on the metal-centered luminescence of the $\mathrm{Yb}^{\mathrm{III}}$ helicate, $W_{\mathrm{ET}}$ must be significantly larger than $k_{o x}$. This is unexpected given that the energy transfer rate constant of the triplet state to the ${ }^{2} \mathrm{~F}_{5 / 2}$ emitter level is usually considered to be $10^{6} \mathrm{~s}^{-1}, 38$ in view of the extremely small spectral overlap between the emission spectrum from the triplet state and the absorption spectrum of the $\mathrm{Yb}^{\mathrm{III}}$ ion. ${ }^{38,41,41}$ One may therefore suspect that another mechanism is operative for the ligand-to- $\mathrm{Yb}^{\mathrm{III}}$ energy transfer. In the cases of lanthanide chelates bearing an aromatic side-chain ${ }^{48}$ and of complexes with proteins, ${ }^{49}$ other authors have proposed that sensitization of $\mathrm{Yb}^{\mathrm{III}}$ occurs via a long-range electron transfer process involving $\mathrm{Yb}^{\mathrm{II}}$. Such a mechanism has been confirmed for a variety of complexes. ${ }^{49}$ More recently, ultrafast time-resolved spectroscopy has also authenticated this mechanism for the (bipy.bipy.bipy) cryptand.$^{9}$ We have investigated the $\mathrm{Yb}^{\mathrm{III}}$ helicate under similar experimental conditions and found that the rise time of the metal-centered emission is extremely fast $\left(\tau_{\text {rise }}<8 \mathrm{~ns}\right)$. In summary, this information, combined with the absence of oxygen quenching and the fact that the intensity of the ${ }^{1} \pi \pi^{*}$ emission decreases drastically upon formation of the helicate, points to a very fast energy transfer process, compatible with the electron transfer mechanism, although not proving it.

\section{Conclusion}

Metal-centered luminescence is fairly well sensitized in the triple stranded homodimetallic helicates $\left[\mathrm{Ln}_{2}\left(\mathrm{~L}^{\mathrm{C}}-2 \mathrm{H}\right)_{3}\right], \mathrm{Ln}=$ $\mathrm{Sm}\left(\mathrm{H}_{2} \mathrm{O}, \mathrm{D}_{2} \mathrm{O}\right)$ and $\mathrm{Yb}\left(\mathrm{D}_{2} \mathrm{O}\right)$. The absolute quantum yield of the ligand-centered luminescence decreases dramatically upon formation of the helicates because of a large enhancement in the intersystem crossing rate constant and subsequent energy transfer onto the metal ions results in the observation of metalcentered luminescence. Both the quantum yields and lifetimes of the metal-centered luminescence of the helicates in $\mathrm{D}_{2} \mathrm{O}$ are large compared to other values reported in the literature, pointing to these systems as potential luminescent probes for applications in bioanalyses. Indeed, ligand $\mathrm{L}^{\mathrm{C}}$ can be easily derivatized in the 4-position of the pyridines ${ }^{50}$ so that grafting of adequate sensitizing groups is within reach.

Pioneer work for the calculation of energy transfer rates and emission quantum yield in the $\mathrm{Sm}^{\mathrm{III}}$ helicate leads to a good agreement between experimental and theoretical quantum yield of the metal centered emission, indicating that the theoretical approach used is adequate. We have shown that the main energy stream from the ligand to the metal ion goes through the triplet state through an exchange mechanism. This type of theoretical modeling of energy transfer processes opens the way for a more rational design of samarium luminescent probes.

Acknowledgment. We gratefully acknowledge Professor Jörma Hölsä (University of Turku) for providing the wave functions of $\mathrm{Sm}^{\mathrm{III}}$ in $\mathrm{SmOCl}$ and $\mathrm{Mr} \mathrm{M}$. Hollenstein (University of Bern) for the synthesis of the ligand. F.R.G.S. is indebted to $\mathrm{CNPq}$ (Brazilian agency) for a stipend. This work is supported through grants from the Swiss National Science Foundation.

\section{References and Notes}

(1) Bünzli, J.-C. G. In Lanthanide Probes in Life, Chemical and Earth Sciences. Theory and Practice; Bünzli, J.-C. G., Choppin, G. R., Eds.; Elsevier Science: Amsterdam, 1989.

(2) Parker, D. Coord. Chem. Rev. 2000, 205, 109.

(3) Yam, V. W. W.; Lo, K. K. W. Coord. Chem. Rev. 1999, 184, 157

(4) Hemmilä, I.; Ståhlberg, T.; Mottram, P. Bioanalytical Applications of Labeling Technologies: Wallac Oy: Turku, Finland, 1995.

(5) Mathis, G. In Rare Earths; Saez Puche, R., Caro, P., Eds.; Editorial Complutense: Madrid, 1998.

(6) Capecchi, S.; Renault, O.; Moon, D.-G.; Halim, M.; Etchells, M.; Dobson, P. J.; Salata, O. V.; Christou, V. Adv. Mater. 2000, 12, 1591.

(7) Hemmilä, I. J. Alloys Compnds. 1995, 225, 480.

(8) Maupin, C. L.; Parker, D.; Williams, J. A. G.; Riehl, J. P. J. Am. Chem. Soc. 1998, 120, 10563.

(9) Faulkner, S.; Beeby, A.; Carrié, M.-C.; Dadabhoy, A.; Kenwright, A. M.; Sammes, P. G. Inorg. Chem. Commun. 2001, 4, 187.

(10) Wolbers, M. P. O.; Van Veggel, F. C. J. M.; Peters, F. G. A.; Van Beelen, E. S. E.; Hofstraat, J. W.; Geurts, F. J.; Reinhoudt, D. N. Chem. Eur. J. 1998, 4, 772 .

(11) Elhabiri, M.; Scopelliti, R.; Bünzli, J.-C. G.; Piguet, C. J. Am. Chem. Soc. 1999, 121, 10747.

(12) Bünzli, J.-C. G.; Piguet, C. In Encyclopedia of Materials: Science and Technology; Pergamon: New York, 2001; Vol. 5, p $446 \mathrm{ff}$.

(13) de Sá, G. F.; Malta, O. L.; Donega, C. D.; Simas, A. M.; Longo, R. L.; Santa-Cruz, P. A.; da Silva, E. F. Coord. Chem. Rev. 2000, 196, 165.

(14) Gonçalves e Silva, F. R.; Longo, R. L.; Malta, O. L.; Piguet, C.; Bünzli, J.-C. G. Phys. Chem. Chem. Phys 2000, 2, 5400.

(15) Bünzli, J.-C. G.; Mabillard, C. Inorg. Chem. 1986, 25, 2750.

(16) Wolsey, W. C. J. Chem. Educ. 1973, 50, A335.

(17) Glasoe, P. K.; Long, F. A. J. Phys. Chem. 1960, 64, 188

(18) Skoog, D. A.; West, D. M. Principles of Instrumental Analysis; Holt, Rinehart and Winston: New York, 1971.

(19) Meech, S. R.; Phillips, D. C. J. Photochem. 1983, 23, 193.

(20) Magde, D.; Brannon, J. H.; Cremers, T. L.; Olmsted, J., III. J. Phys. Chem. 1979, 83, 696

(21) Houten, J. V.; Watts, R. J. J. Am. Chem. Soc. 1976, 98, 4853.

(22) Charles, R. G.; Ohlmann, R. C. J. Inorg. Nucl. Chem. 1965, 27, 255. 
(23) Meshkova, S. B.; Topilova, Z. M.; Bolshoy, D. V.; Beltyukova, S. V.; Tsvirko, M. P.; Venchikov, V. Y. Acta Phys. Polonica A 1999, 95 983.

(24) Malta, O. L. J. Lumin. 1997, 71, 229.

(25) Malta, O. L.; Gonçalves e Silva, F. R. Spectrochim. Acta A 1998 , $54,1593$.

(26) Carnall, W. T., Crosswhite, H, and Crosswhite, H. M. Energy Level Structure and Transition Probabilities of the Trivalent Lanthanides in $\mathrm{LaF}_{3}$; Argonne National Laboratory: Argonne, IL, 1997.

(27) Malta, O. L.; Gonçalves e Silva, F. R.; Longo, R. L. Chem. Phys. Lett. 1999, 307, 518.

(28) Gonçalves e Silva, F. R.; Malta, O. L. J. Alloys Compnds. 1997, $250,427$.

(29) Malta, O. L.; Brito, H. F.; Menezes, J. F. S.; Gonçalves e Silva, F. R.; Alves Jr., S.; Farias, F. S., Jr.; De Andrade, A. V. M. J. Lumin. 1997, $75,255$.

(30) De Andrade, A. V. M.; Longo, R. L.; Simas, A. M.; de Sá, G. F. J. Chem. Soc., Faraday Trans. 1996, 92, 1835.

(31) Carnall, W. T.; Fields, P. R.; Rajnak, K. J. Chem. Phys. 1968, 49, 4424.

(32) Rodriguez-Ubis, J.-C.; Sedano, R.; Barroso, G.; Juanes, O.; Brunet, E. Helv. Chim. Acta 1997, 80, 86.

(33) Kimura, T.; Kato, Y. J. Alloys Compnds. 1995, 225, 284.

(34) Xu, Y. Y.; Hemmilä, I.; Lövgren, T. Analyst 1992, 117, 1061. 67.

(35) Morin, M.; Bador, R.; Dechaud, H. Anal. Chim. Acta 1989, 219,

(36) Rigault, S.; Piguet, C.; Bünzli, J.-C. G. J. Chem. Soc., Dalton Trans. 2000, 2045 .

(37) Gamelin, D. R.; Luthi, S. R.; Güdel, H. U. J. Phys. Chem. B 2000, 104, 11045 .
(38) Klink, S. I.; Grave, L.; Reinhoudt, D. N.; Van Veggel, F. C. J. M. Werts, M. H. V.; Geurts, F. A. J.; Hofstraat, J. W. J. Phys. Chem. A 2000 104, 5457.

(39) Dickins, R. S.; Howard, J. A. K.; Maupin, C. L.; Moloney, J. M.; Parker, D.; Riehl, J. P.; Siligardi, G.; Williams, J. A. G. Chem. Eur. J. 1999, 5, 1095.

(40) Werts, M. H. V.; Verhoeven, J. W.; Hofstraat, J. W. J. Chem. Soc. Perkin Trans. 2 2000, 433.

(41) Klink, S. I.; Hebbink, G. A.; Grave, L.; Van Veggel, F. C. J. M. Reinhoudt, D. N.; Slooff, L. H.; Polman, A.; Hofstraat, J. W. J. Appl. Phys. 1999, 86, 1181.

(42) Wolbers, M. O.; Van Veggel, F. C. J. M.; Snellink-Rüel, B. H. M.; Hofstraat, J. W.; Geurts, F. A. J.; Reinhoudt, D. N. J. Chem. Soc., Perkin Trans. 2 1998, 2141.

(43) Buono-Core, G. E.; Li, H.; Marciniak, B. Coord. Chem. Rev. 1990 $99,55$.

(44) Malta, O. L.; Brito, H. F.; Menezes, J. F. S.; Gonçalves e Silva, F. R.; Donega, C. D.; Alves, S. Chem. Phys. Lett. 1998, 282, 233.

(45) Petoud, S.; Bünzli, J.-C. G.; Glanzman, T.; Piguet, C.; Xiang, Q.; Thummel, R. P. J. Lumin. 1999, 82, 69.

(46) Guldi, D. M.; Mody, T. D.; Gerasimchuk, N. N.; Magda, D.; Sessler,

J. L. J. Am. Chem. Soc. 2000, 122, 8289.

(47) Murov, S. L.; Carmichael, I.; Hug, G. L. Handbook of Photochemistry; M. Dekker Inc.: New York, 1993.

(48) Abusaleh, A.; Meares, C. F. Photochem. Photobiol. 1984, 39, 763.

(49) Horrocks, W.deW. Jr.; Bolender, J. P.; Smith, W. D.; Supkowski,

R. M. J. Am. Chem. Soc. 1997, 119, 5972

(50) Platas, C.; Elhabiri, M.; Hollenstein, M.; Bünzli, J.-C. G.; Piguet, C. J. Chem. Soc., Dalton Trans. 2000, 2031. 